\title{
Implementation of Web-Based Technologies into Teaching and Learning Practices in the University
}

\author{
M. S. Lyashenko
}

\begin{abstract}
The rapid penetration of web-based technologies into our social life creates challenges both for teachers and students to face. The paper dwells upon the implementation of social media as web-based technologies into the educational environment in the university. Social media application is considered at macro and micro levels within the university structure. Particular attention is paid to the description of LMS system at a macro level and a group wiki site at a micro level. The advantages and disadvantages of the technologies at both levels are identified. The author proposes the idea that particular pedagogical conditions must be created for successful deployment of the technologies. The participative approach is suggested as a basis of teacher-student collaboration.
\end{abstract}

Index Terms-Participative approach, social media, web-based technologies, wiki sites.

\section{INTRODUCTION}

The rapid pace at which new technologies are entering our life has raised the issues that teachers have to solve: what technologies to use? How? When and why? The challenges that both teachers and learners are faced with are associated with the tools, technologies and systems of e-learning. E-learning is considered to be the third learning system that makes use of various electronic technologies, forms and components as its primary means of learning and teaching [1]-[3]. Both educators and learners have to choose from the variety of forms when being in a new educational environment. E-learning involves various technologies (TV, the internet, computers, software products for education etc), various components (e-books and dictionaries, e-libraries etc), various formats (e-learning courses and programmes, virtual learning centers, online programmes, virtual universities). More than 100 web-based technologies and software products are being used for educational purposes by the teachers and learners worldwide. Social media are topping the annual list of the most popular tools for learning [4]. Social media are considered to be an integral part of e-learning nowadays [5]-[7]. Many researchers point to the educational potential of social media tools [8].

We would like to focus the attention on the types of web-based technologies which are used by the authors for English language teaching (ELT) in the National Research University Higher School of Economics in general paying special attention to a specific social media- wiki-sites created as non- institutional learning platform for teacher-student collaboration. In our research we mainly describe the

Manuscript received July 12, 2014; revised October 22, 2014.

M. S. Lyashenko is with the National Research University Higher School of Economics Nizhniy Novgorod, Russia (e-mail: mslyashenko@mail.ru). implementation of institutional and non-institutional web-based tools in formal and informal levels of T-S interaction.

\section{IMPLEMENTATION OF WEB-BASED TECNOLOGIES IN THE UNIVERSITY}

\section{A. Formal (Institutional) Level}

\section{1) Background}

Web-based technologies are defined in different ways. In this paper we would use the definition advanced by $\mathrm{C}$. Wankel who defines these tools as "any form of on-line technology or practices through which users create communities to convey information ideas, independent learning, entertainment, collaboration and personal messages and thus facilitates communication and interaction between individuals and groups" [9]. Web-related technologies as social media are used in universities at a macro level (formal) and a micro level (interpersonal and informal) [10], [11]. On a formal (macro) level social media, especially a social network, demonstrates how a large group of people are connected to one another (campuses, departments, faculties, groups etc). An informal level (micro) level consists of all the people, friends, family and others - with whom one shares a social relationship [10].

Scientists note that social media at a micro level are used mainly for entertainment purposes and its educational potential is sometimes ignored by the educators despite its wide spread and popularity among students [8].

Social media for teacher- student (T-S) collaboration can be classified into the following categories [12]:

1) blogs and microblogs (for example, Twitter)

2) content communities (for example, YouTube and quizlet.com, podcasts etc. )

3) social networking sites (for example, Facebook)

4) collaborative projects (for example, Wikisites ).

At a formal level most of these types are successfully integrated into the Learning Management System (LMS) based on a Moodle platform. A Moodle platform is generally used to support blended learning and includes external collaboration. In the computer dictionary LMS is defined as a software application or Web-based technology used to plan, implement and assess a specific learning process [13].

2) Learning management system in the higher school of economics

The Learning management system (LMS) has been developed in the National Research University, the Higher School of Economics (HSE) Nizhny Novgorod since 2010. The purpose of the system is to increase the level and the 
quality of methodical, didactic, information support for educational process for all the participants: students, teachers, and managers of different faculties. LMS is aimed at achieving the following goals:

- enabling learning practices in the active environment of all the participants on - line and off - line

- enhancing students' involvement into active educational process;

- creating conditions for active interaction between students and teachers;

- improving digital skills of teachers and students

The priority is given not to technical and instructional consulting but better teacher-student (T-S) and teacher-teacher (T-T) interaction. It offers a more individual approach to learning and teaching [14]. This system helps produce, manage and integrate knowledge in the higher school. Besides, the LMS can be used to develop a variety of educational products (for example, a virtual library of tests, interactive vocabulary practice programs, grammar activators, language laboratories, etc) to support the needs of particular groups.

The system offers obvious advantages and benefits but both teachers and students are reluctant to use the system. Implementation of the LMS in the university is associated not only with the merits that could be brought to the university but also with some criticism of the system itself. Scientists in this filed state that clear principles of implementation have not been developed yet [15]. In order to implement the system effectively, the university in general [16] and lecturers and teachers in particular [17] must play an active part in LMS integration processes.

\section{3) Research and the results}

To better know what problems LMS users face in the HSE we conducted a research among the students and the teachers who learn and teach a foreign language (mainly English, German). We expected the users to share their positive experience when working in the LMS to find out more about the advantages and disadvantages of the LMS system. The research made it possible to identify the problems that discourage and the advantages that motivate the learners to work within the LMS system. Two sets of questionnaires were worked out to cover two target audiences: students and teachers. The questionnaires in the research ask about the problems and advantages of the system from the users' point of view. The analysis of the responses pointed to the fact that the majority of students does not enjoy working in the LMS (53\% respondents) and $47 \%$ of the respondents approve the use of the LMS and are enthusiastic about it. The difference is not so great to give evidence that LMS is not attractive for students. As for the teachers, $60 \%$ of the respondents think positively and are motivated to incorporate the LMS into teaching. One quarter does not see the necessity to apply it unless it is imposed from above. $15 \%$ of the respondents think there is no point using the system at all as it distracts students' attention from the essence of the subject. Such unwillingness can be explained, to some extent, by technological hurdles that make the usage time-consuming and effort taking.

According to the findings the main complaints about the system cover the following problems:

1) Problems with interface (small font, difficulty to find the necessary information, too many functions) -design and visual presentation.

2) Technical glitches (inability to get an access from home or a mobile phone, difficulty to attach or delete files, inconvenient message delivery system) -technology.

3) Openness of knowledge that on the one hand simplifies cheating, plagiarism on the other hand, makes assessment and control system, teacher-student interaction more transparent -pedagogical aspect.

The most interesting finding for the research was the statistics showing that more than one third of the learners out of 40 students- participants $(32,5 \%)$ think that mail services or social networks are more convenient and less consuming to share and disseminate the information. The students consider the LMS as an academic environment imposed from above. That is why they prefer less formal and more relaxing ways to exchange and interact [6], [18].

The findings show that in general, the LMS as a web-based technology is considered to be an effective platform for collaboration despite the difficulties and problems the users experience when working in the LMS. The teachers must play a critical role in successful implementation of the system. The positive attitude of the teachers to the system and awareness of its possibilities as a whole can be a critical factor to successful LMS integration into the university structure [14].

\section{B. Informal (Non-Institutional) Level}

\section{1) Wikis: A platform for an informal social learning environment}

Taking into account the theoretical conclusions and practical results of the research and psychological prerequisites associated with the implementation of web-related technologies at a formal level we propose the idea that the teachers should switch to less formal social media tools and find non-traditional psycho-pedagogical approaches how to build the atmosphere of collaborative learning and help learners develop through motivational sphere. According to the psychological theory of activity advanced by Rubinstein (1940) the success and effectiveness of learning activity is based on the interest the learner has towards the task he is doing. It is necessary to underline that the processes of teaching and learning should not be opposed to each other. On the contrary, the process of teaching is a unified process including both a teacher and the student and their interaction and collaboration [19].

The paper focuses mainly on Wikis as an opportunity for collaborative projects. Using Google sites the author has created a wiki site for teaching and learning purposes to collaborate effectively with the students and engage them into studying process.

Google wiki sites can be used to solve a variety of teaching problems and tasks. They are created to support a particular discipline. Such a technology provides the teacher and students with the opportunity to download and upload the information, to get an easy access to the materials and do projects. The sites could be a virtual platform for e-learning within the university structure. Besides this tool allows the 
teacher to combine different ICT: forums, blogs, media stores. For example, it could be used to store students' papers or presentations [20]. In our case wiki site is used not as the main tool but a scaffolding platform for collaboration at an informal level. As pointed out by McLoughlin [21] scaffolding is a form of learner support provided in a various ways, assigning a number of roles and responsibilities for students, lecturers, instructors, experts and other participants in the educational environment .

\section{2) Case study: A group wiki site for ELT (English language teaching)}

The wiki site, which is created on a Google platform, [22] is an example of an educational wiki with its basic features: source code, wiki management, access control, communications, support and advanced features The research in the sphere of educational wikis showed that university wikis are commonly used as a means of knowledge repositories to upload and download official information [23]. The idea of creating a wiki site within this research project was to create a group wiki for the 1st year students of management faculty in the Higher School of Economics Nizhny Novgorod. This type of a site targets micro interactions at an interpersonal level [11]. This feature makes it less formalized and more customized and tailored to the needs of a particular group and individual students. Less academic level of collaboration helps identify problem zones of a target group and provide the immediate and instantaneous feedback through the system of forums and blogs. Moreover, it enables to use a variety of e-forms from texts with hyper links, interactive glossaries, on line tests, presentations, projects. Teachers can create a variety of interactive activities and products from virtual libraries that are collaboratively enriched by the sources and language laboratories focused on a certain problem area (listening skills or writing) to simple group discussions. Wikis are believed to offer a flexibility of interaction that allows facing any external and internal challenges (age factor, cultural diversity, psychological reluctance etc). Teaching and learning becomes more individualized making students feel less restrained and shy but more confident and relaxed [6].

As an example of one of the teaching practices how to work with the wiki to engage the students is the example explaining grammar through a series of power point presentations created by the teacher and downloaded to the site. This is an example of flipping -the- class strategy when Video for the lessons (from Youtube) and grammar material can be delivered through the site for further class discussion The other example may be delivery of students' presentation related to the topic with further class discussion [20].

\section{3) Criticism on social media}

Despite the advantages and opportunities wikis provide, we cannot ignore some criticism on social media. The problems that can arise when implementing Wiki or other web-related technologies can be categorized in the following groups:

1) technological (for example, inefficient capabilities of the platform (size, interface, dependence on good internet connection etc);

2) psychological (hindering real life socializing, distortions in interpersonal relationships, personality clashes, etc);
3) educational connected with the content control and power sharing (reluctance to share the personalized content because of cheating, plagiarism, bullying; reliability of information uploaded into a collaborative project; language style etc) [11], [24];

4) pedagogical (difficulty of assessment of individual contribution and establishing criteria for evaluation, time, creativity and originality etc)

5) socio-economic and cultural ( the problem of " digital divide" in terms of social structure and existence between haves and have-nots users or cultural clashes).

\section{PEDAGOGICAL CONDITIONS FOR IMPLEMENTATION OF WEB-BASED TECNOLOGIES IN THE UNIVERSITY}

New educational tools require that teacher-student (T-S) interaction must be changed. E-learning makes learners more autonomous and modifies the role of a teacher. So, the teacher is indispensable in planning, implementing, supporting, correcting and adapting or changing knowledge delivery according to the educational needs.

From our perspective, T-S interaction should be based on collaboration and a participative approach.

New forms of asynchronous education require new approaches to teacher-student interaction as this type of communication is based on "different time-different place" mode [25]. The role of a teacher becomes more complicated: he/she takes the responsibility to create, develop, incorporate, coordinate, consult and share expertise with the learners. As teaching nowadays would require tutors to have the ability and pedagogical skills to combine new technologies with the traditional ones, the proposed participative approach can be used as a means of facilitating not only professional development of the teachers themselves but also pedagogical communication. Teachers are expected to work paying more attention to students' autonomy and independence. Participative approach as a practice-oriented tactics of subject-subject interaction in the educational system involves solving problems based on the participation and involvement of students on an equal basis. Following Nikitina [26], we believe that the application of a participative approach to T-S interaction will mean:

1) the right to have one's own opinion in doing tasks and assignments;

2) counseling, seeking agreement between the teacher and students;

3) pedagogical communication on the basis of parity and tolerance and voluntary participation.

The application of the approach will be affective if certain pedagogical conditions are created and maintained. Firstly, the priority is given to the motivation of both teachers and students to interact and collaborate. Without establishing a friendly rapport with the target group and within the group at a micro (informal) level the instructor is unlikely to expect any positive outcome. Individual approach to every participant of education process lies at the basis of the participative approach. Finally, the education process must be technologised at a macro university level to enable teachers incorporate web-based technologies in every-day teaching and learning practices. 


\section{CONCLUSION}

One of the possible ways how to overcome the problems while incorporating web-related technologies into the traditional system of education in general and teaching a foreign language in particular is the balanced combination of e-learning components and technologies with participative approach to T-S interaction. Web-based technologies can be categorized as motivational tool technologies appealing to students' cognitive, emotional, and behavioral engagement [27] which are characterized by such attributes as: innovation, easy usage and sharing, content control, motivational appeal etc. The future investigations can be directed towards psycho-pedagogical and educational potential that these technologies possess and offer for teacher- student collaboration.

\section{REFERENCES}

[1] I. Snyder, Page to Screen: Taking Literacy into the Electronic Era, New York, NY: Routledge, 1998.

[2] M. J. Rosenberg, E-Learning: Strategies for Delivering Knowledge in the Digital Age, New York, NY: McGraw-Hill, 2001.

[3] J. E Bowman, A. Holmes and K. Swan, "Virtual teacher education: affordances and constraints of teaching teachers online," in J. Price $e$ al. Eds., in Proc. Society for Information Technology and Teacher Education International Conference, May 2014, p. 7961.

[4] Center for Learning and Performance Technology-CALPT. (July 2014) Top 100 tools for learning 2013. [Online]. Available: http://c4lpt.co.uk/top100tools/

[5] A. J. Turgeon, "Implications of web-based technology for engaging students in a learning society," Journal of Public Service \& Outreach, vol. 2, pp. 32-37, November 1997.

[6] A. Dalton. (July 2014). Teaching and learning through social networks. [Online]. Available: http://www.teachingenglish.org.uk/article/teaching-learning-throughsocial-networks

[7] Y. Liu, "Social media tools as a learning resource," Journal of Educational Technology Development and Exchange, vol. 3, pp. 101-114, October 2010.

[8] B. Chen and T. Bryer, "Investigating instructional strategies for using social media in formal and informal learning," The International Review of Research in Open and Distance Learning, vol. 13, January, 2012.

[9] C. Wankel, Cutting Edge Social Media Approaches to Business Education, Information Age Publishing, 2010, pp. 1-5.

[10] S. Golder, D. Wilkinson, and B. Huberman. (July 2014). Rhythms of social interaction: messaging within a massive online network. [Online]. Available: http://www.hpl.hp.com/research/scl/papers/facebook/facebook.pdf

[11] J. Cummins, "Minority status and schooling in Canada," Anthropology and Education Quarterly, vol. 2893, pp. 411-430.

[12] A. M. Kaplan and M Haelein, "Users of the world, unite! The challenges and opportunities of social media," Business Horizon, vol. 53, pp. 59-68, 2010.

[13] Computer dictionary. (July 2014). [Online] Available: http://searchcio.techtarget.com/definition/learning-management-syste $\mathrm{m}$

[14] R. Whelan and D. Bhartu. (May 2014). Factors in the development of a learning management system at a large university. Ascilite Singapore
2007.

[Online].

Available:

http://www.ascilite.org.au/conferences/singapore07/procs/whelan.pdf.

[15] J. Pratt, "The fashionable adoption of on-line learning technologies in Australian universities," Journal of the Australian and New Zealand Academy of Management, vol. 11. no. 1, p. 57, 2005.

[16] J. Ulmer and J. Leech, "Learning management deployment and integration: policy, requirements, and technical solutions," in G. Richards, Ed., in Proc. World Conference on e-Learning in Corporate, Government, Healthcare, and Higher Education, pp. 1137-1142, 2005.

[17] I. Doherty and M. Honey, "Taking ownership of technology: Lecturers as LMS learners," in Proc. the $23^{\text {rd }}$ Annual Conference of the Australasian Society for Computers in Learning in Tertiary Education: Whose Learning? Whose Technology? p. 35, April 2014.

[18] Kern and M. Baldissera. (April 2014). Moodle or Facebook? An experience with moodle UFRGS LMS in the teaching of art history, theory and criticism at graduate level. [Online]. Available: http://conference.pixel-online.net/edu_future2012/common/download /PPT_pdf/ENT21.pdf.

[19] S. L. Rubinstein, Basics of Psychology, St. Petersburg: Piter, 2002.

[20] Intbusinesspreinterm. [Online]. Available: https://www.sites.google.com/site/intbusinesspreinterm/presentationslang-leader

[21] C. McLoughlin, "Learner support in distance and networked learning environments: Ten dimensions for successful design," Distance Education, vol. 23, no. 2, pp. 150-162, 2002.

[22] Intbusinesspreinterm. [Online]. https://www.sites.google.com/site/intbusinesspreinterm/home

[23] L. Schwartz, S. Clark, M. Cossarin, and J. Rudolphin, "Educational Wikis; features and scientific criteria," The International Review of Research in Open and Distance Learning, vol. 5, no. 1, 2004.

[24] P. Rambe, "Exploring the impacts of social networking sites on academic relations in the university," Journal of Information Technology Education, vol. 10, pp. 271-293, 2011.

[25] J. Ashley. (July 2014). Synchronous and asynchronous communication tools. [Online]. Available: http://www.asaecenter.org/Resources/articledetail.cfm?itemnumber=1 3572

[26] E. U. Nikitina, Pedagogical Management of Communicative Education of Students: Perspective Approaches, Moscow: MNPO, 2006.

[27] N. Pino James. (July 2014). 4 free web tools to boost student engagement. [Online]. Available: http://www.edutopia.org/blog/web-tools-boost-student-engagement-ni colas-pino-james

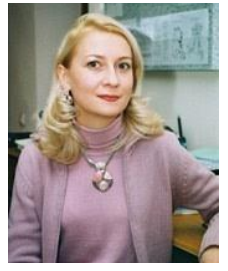

Mariya Lyashenko was born in Russia, Nizhniy Novgorod, on November 20, 1976. She was graduated with honors the Nizhniy Novgorod Linguistic University after N. A. Dobrolyubov in 1999. In 2009 she wrote and defended the thesis "The formation of the psycho-pedagogical culture of students in higher school". The degree $\mathrm{PhD}$ in professional education was earned in 2010 at Mininsky University, Nizniy

Novgorod, Russia.

She has been working for the National Research University Higher School of economics (HSE Nizhniy Novgorod) since 2000. Her current position is an assistant professor of Foreign Languages Department in HSE Nizhniy Novgorod, Bolshaya Pecherskaya Street, 25/12, 603155. She has more than 30 publications, 2 monographs. The latest published article is "LMS projects: a platform for intergenerational learning" in education and information technologies, 2014. 